\title{
Discursos humorísticos e identidad de género
}

Discursos humorísticos e identidad de género incluye estudios vinculados a distintas disciplinas del saber, entre ellas filosofía, historia, sociología, lingüística, literatura (española, francesa e inglesa), arte gráfico, música, dramaturgia o redes sociales que abordan cuestiones relativas a la construcción y deconstrucción del género en el marco del sistema patriarcal desde la perspectiva del humor. Como fuente de diversión, como vía de comunicación interpersonal, como elemento de creación artística, como herramienta de denuncia social, como experiencia cognitiva de descubrimiento de realidades, como elemento catártico, como mecanismo psicológico de defensa ante la adversidad o como fórmula terapéutica para reparar traumas, el humor ha sido materia de análisis a lo largo de la historia, de especial trascendencia son los tratados al respecto de Platón y Aristóteles ${ }^{1}$ en la Grecia Clásica, de Laurent Joubert ${ }^{2}$ en el Renacimiento o de Sigmund Freud $^{3}$ en el siglo XX. En la actualidad gana fuerza como objeto de estudio en muy diversos campos de investigación, muestra de ello es este monográfico, en el que las autoras analizan producciones culturales en las que se representan diferentes identidades de género a través de elementos cómicos, en ellas, el humor se emplea como recurso creativo para examinar el modo en el que se construyen, se difunden o se subvierten determinados prototipos de feminidad y masculinidad que encasillan al sujeto - limitando sus posibilidades de desarrollo personal- al tiempo que lo adscriben a una determinada posición -central-marginal, superior-inferior, dominante-subordinada-.

Apunta Stefan Vanistendael que "el humor surge con frecuencia de un defecto de la realidad, de algo que no es exactamente correcto o que no es correcto en absoluto" (2013:12). El humor agudiza la conciencia del ser humano (Alasia de Bosch en Caron y Caron, 2004:21) con independencia de su origen, de su lengua, de su cultura, de su edad, de su sexo o de su clase social y le incita a discurrir en torno a lo que correcto o incorrecto y a compartir sus reflexiones de una forma más placentera. Quienes suscriben los trabajos presentes en esta publicación estiman que el sistema patriarcal es un mal que hay que corregir y lo sitúan en el centro del debate social.

Si bien existen un número nada insustancial de trabajos que utilizan el humor como prisma desde el que examinar el género, estos, por lo general, arrojan luz sobre las estrategias que emplean los hombres para generar efectos cómicos o sobre la representación que hacen estos -desde la posición de superioridad que le otorga el patriarcado- de las mujeres como objeto humorístico. Sin embargo, el fenómeno de la mujer como sujeto creador de comicidad ha sido desatendido, en gran medida, por quienes teorizan sobre el fenómeno. En esta línea puntualiza Virginia Imaz:

Es cierto que las mujeres hemos sido, al igual que en otros menesteres, más a menudo objetos que sujetos del hecho humorístico. Esto es, hemos sido, seguimos siéndolo, tema para reír de las diferentes comunidades humanas, junto con otros colectivos de diferentes, excluidos, minorías, etc. [...]. Las mujeres como creadoras de humor resultamos ser un fenómeno algo menos habitual o, cuando menos, peor valorado y documentado históricamente (Imaz 2005:7).

Esta particularidad implica la existencia de una laguna de conocimiento porque, siguiendo los planteamientos de Regina Barreca, hay notables diferencias entre el humor que producen los hombres y el que generan las mujeres, el que presentan los primeros equivale a "una revuelta" y el que manifiestan las segundas "una revolución" (Barreca 1994:16). Es de vital importancia que haya estudios marco que presenten referentes femeninos en la materia, que permitan reconocer la

\footnotetext{
1 Disquisiciones en torno al humor y a la risa encontramos en Filebo, República o Las Leyes de Platón, así como en Poética, Retórica y Ética a Nicómaco de Aristóteles.

2 Véase El Tratado de la Risa (1579).

3 Véase El humor (1928) y El chiste y su relación con lo inconsciente (1905).
} 
originalidad, el ingenio y el potencial cómico de las mujeres y que establezcan una genealogía de creadoras de humor que sirva de guía a posteriores generaciones.

En una sociedad que discrimina, reprime y subyuga a las mujeres, el lenguaje humorístico femenino, señala Nancy Walker (1988:29), estrechamente ligado al hogar, la maternidad o las relaciones de pareja, conlleva más angustía y frustración que diversión. La risa les ayuda a afrontar lo cotidiano, es a la vez un elemento de catarsis porque les ayuda a liberar tensiones y, por tanto, a reducir el sufrimiento y una herramienta de subversión porque les permite compartir el descontento y denunciar las situaciones que las oprimen como colectivo. Gracias a ella pueden adquirir visibilidad, alzar la voz y ganar en agencia, por lo que se erige en un potente mecanismo de resistencia ante la adversidad, de subversión contra el poder dominante y de resiliencia frente a traumas y heridas fruto del sometimiento al que están sujetas.

Este monográfico se funda, por tanto, en el convencimiento de que es necesario difundir trabajos académicos que reflexionen en torno a la naturaleza y las características del humor que generan, en sus producciones, pensadoras, escritoras, artistas, viñetistas, cineastas, dramaturgas, etc. A través de este elemento, nos presentan su visión del mundo, en general, y de los roles de género, en particular, usando múltiples estrategias discursivas en las que los juegos de palabras, la ironía, la sátira, el sarcasmo, la hipérbole o lo esperpéntico ocupan un lugar destacado para, por un lado, mofarse de $-\mathrm{y}$ con ello restar vigor a- las normas, las costumbres, las leyes y los estereotipos de masculinidad y feminidad que ha construido e impuesto el patriarcado al objeto de que los varones sean los que ejerzan el poder desde una posición central y dominante, y, por otro, promover nuevas concepciones de género que no respondan a este esquema y que sirvan para impulsar una sociedad menos prejuiciosa, más libre, justa e igualitaria. Al tiempo que invitan a la reflexión mostrando lo absurdas, ridículas y pretenciosas que son las bases sobre los que se sustenta la identidad de género codificada en clave patriarcal, los artículos de esta publicación pretenden provocar una sonrisa cómplice.

María Elena Jaime de Pablos se centra en la escritora irlandesa Ann Enright y su relato corto "The Portable Virgin" (1991) en el que se parodian los mitos sobre los que se sustenta la identidad femenina en el marco del sistema patriarcal católico: el de la Virgen María, modelo positivo de virtud, y el de María Magdalena, modelo negativo de vida pecaminosa. A través de un humor feminista y subversivo, Enright muestra la naturaleza perversa de este orden social que encorseta, polarizándolo, el desarrollo personal de las mujeres y alerta sobre los efectos nocivos que este fenómeno produce en su psique.

Dentro también del género narrativo, Isabel Esther González Alarcón explora la novela Le baobab fou (1984) de la escritora senegalesa Ken Bugul. Desde una perspectiva sociocultural y sirviéndose de elementos cómicos como categoría de análisis, examina la difícil transición que experimentan las africanas que, rompiendo con la tradición, han abandonado sus respectivos países con el fin de alcanzar su emancipación como sujetos con voz y agencia.

En el género teatral, Milagro Martín-Clavijo analiza el mito de Penélope y con él, o a través de él, también el de Ulises. Desde una mirada diferente y crítica filtrada por el humor, en Penelopeide (2008) la dramaturga italiana Patrizia Monaco presenta una profunda revisión crítica del mito que es claramente postmoderna. En el artículo se analiza el tratamiento irónico y paródico de lo heroico para presentar una construcción de la identidad femenina diferente que supone una clara subversión del pensamiento dominante.

María Rosal Nadales nos acerca al mundo de la cultura popular a través de la copla española, muy particularmente la de Rafael de León, durante la dictadura franquista y nos señala la relevancia de este género musical en la educación sentimental que recibieron un sinfín de mujeres españolas de distintas generaciones. Rosal Nadales analiza la parodia que entrañan diversas letras con el propósito de criticar los modelos patriarcales que se difundían bajo el régimen de Franco o presentar alternativas a estos.

Finalmente, Trinidad Núñez Domínguez y Teresa Vera Balanza abordan la temática de este monográfico examinando más de cien viñetas de ilustradoras gráficas y viñetistas españolas al objeto de establecer sus características, definir sus ejes temáticas, ponerlas en valor o medir su repercusión mediática. En este sentido, las dos investigadoras subrayan la importancia de que 
compartan y autogestionen su obra a través de las redes sociales, Instagram entre ellas, saliéndose así de los círculos convencionales del mundo empresarial periodístico. Estas artistas, que optan por el compromiso ideológico y abogan por importantes cambios sociales y políticos, consiguen estimular el sentido crítico del público al que se dirigen.

Los cinco artículos que componen este volumen Discursos humorísticos e identidad de género muestran que son muchas las mujeres que han decidido conscientemente representar una realidad sexista con grandes dosis de humor gracias al cual nos invitan a observarla desde una perspectiva diferente y, con ello, a revisar una serie de prejuicios, de mitos o de prototipos de masculinidad y feminidad arcaicos, a reflexionar sobre las desigualdades políticas, sociales y económicos que diferencian a los individuos, a abordar cuestiones relativas a la identidad, al cuerpo, a la sexualidad, etc. Su humorismo, fundado en una visión de cambio (Kaufman y Blakley, 1980:13), sirve para establecer y representar una comunidad de preocupaciones compartidas (Walker, 1991:60) frente a las instituciones, poderes y convenciones que imponen su criterio de género a la ciudadanía.

Porque se opone al sistema patriarcal que neutraliza a las mujeres, porque facilita la resistencia a los discursos dominantes de la cultura hegemónica, porque denuncia lo que no es correcto desde el punto de vista ético, porque cuestiona todo lo que se nos ha presentado como natural $y$, por tanto, inmutable, podemos calificar este su humor como subversivo o, empleado terminología de Lisa Merril (1988:279), rebelde y de autoafirmación.

María Elena JAIME DE PABLOS* Milagro MARTÍN CLAVIJO**

\section{Referencias bibliográficas}

BARRECA, Regina. Untamed and Unabashed: Essays on Women and Humor in British Literature. Detroit, Wayne State University Press, 1994.

CARON, Bettina; CARON, Carlos Maria. Escribir con Humor: Juegos Literarios en el Taller. Buenos Aires, Colihue, 2004.

IMAZ, Virginia. Género y humor. La triple trasgresión. Revista Emakunde n. 59. Monográfico El humor desde el género ¿De qué se ríen las mujeres?, 2005, pp.6-11.

KAUFMAN, Gloria J.; BLAKLEY, Mary Kay. Pulling our own strings: Feminist humor and satire. Bloomington, Indiana University Press, 1980.

MERRIL, Lisa. Feminist humor: rebellious and self-affirming. Hempstead, Hofstra University, 1988.

VANISTENDAEL, Stefan. Sonreír cuando la vida no nos sonríe. Reflexiones sobre el humor, la resiliencia y la espiritualidad. En: VANISTENDAEL, Stefan et al. Resiliencia y humor. Barcelona, Editorial Gedisa, 2013.

WALKER, Nancy A. Toward Solidarity: Women's Humor and Group Identity. In: SOCHEN, June (ed.). Women's Comic Visions. Detroit, Wayne State University Press, 1991, pp.57-81.

WALKER, Nancy A. A Very Serious Thing: Women's Humor and American Culture. Minneapolis, University of Minnesota Press, 1988.

\footnotetext{
* Profesora Titular de Departamento de Filología (Área de filología Inglesa), Universidad de Almería, Almería, España. mjaime@ual.es / orcid.org/0000-0001-6845-7670 ***ofesora Titular, Universidad de Salamanca, Salamanca, España. mclavijo@usal.es / https://orcid.org/0000-0001-
$\underline{\text { 7300-9493 }}$
} 